\title{
Nicotiana attenuata Data Hub (NaDH): an integrative platform for exploring genomic, transcriptomic and metabolomic data in wild tobacco
}

Thomas Brockmöller ${ }^{1}$, Zhihao Ling ${ }^{1}$, Dapeng Li ${ }^{1}$, Emmanuel Gaquerel ${ }^{2}$, lan T. Baldwin ${ }^{1}$ and Shuqing Xu ${ }^{1 *}$ (D)

\begin{abstract}
Background: Nicotiana attenuata (coyote tobacco) is an ecological model for studying plant-environment interactions and plant gene function under real-world conditions. During the last decade, large amounts of genomic, transcriptomic and metabolomic data have been generated with this plant which has provided new insights into how native plants interact with herbivores, pollinators and microbes. However, an integrative and open access platform that allows for the efficient mining of these -omics data remained unavailable until now.

Description: We present the Nicotiana attenuata Data $\mathrm{Hub}(\mathrm{NaDH})$ as a centralized platform for integrating and visualizing genomic, phylogenomic, transcriptomic and metabolomic data in N. attenuata. The NaDH currently hosts collections of predicted protein coding sequences of 11 plant species, including two recently sequenced Nicotiana species, and their functional annotations, 222 microarray datasets from 10 different experiments, a transcriptomic atlas based on 20 RNA-seq expression profiles and a metabolomic atlas based on 895 metabolite spectra analyzed by mass spectrometry. We implemented several visualization tools, including a modified version of the Electronic Fluorescent Pictograph (eFP) browser, co-expression networks and the Interactive Tree Of Life (iTOL) for studying gene expression divergence among duplicated homologous. In addition, the NaDH allows researchers to query phylogenetic trees of 16,305 gene families and provides tools for analyzing their evolutionary history. Furthermore, we also implemented tools to identify co-expressed genes and metabolites, which can be used for predicting the functions of genes. Using the transcription factor NaMYB8 as an example, we illustrate that the tools and data in $\mathrm{NaDH}$ can facilitate identification of candidate genes involved in the biosynthesis of specialized metabolites.
\end{abstract}

Conclusion: The $\mathrm{NaDH}$ provides interactive visualization and data analysis tools that integrate the expression and evolutionary history of genes in Nicotiana, which can facilitate rapid gene discovery and comparative genomic analysis. Because $\mathrm{N}$. attenuata shares many genome-wide features with other Nicotiana species including cultivated tobacco, and hence $\mathrm{NaDH}$ can be a resource for exploring the function and evolution of genes in Nicotiana species in general. The NaDH can be accessed at: http://nadh.ice.mpg.de/.

Keywords: Nicotiana attenuata, Phylogenomics, Transcriptomics, genomics, Metabolomics, Co-expression analysis

\footnotetext{
* Correspondence: sxu@ice.mpg.de

'Department of Molecular Ecology, Max Planck Institute for Chemical

Ecology, Hans-Knöll-Straße 8, D-07745 Jena, Germany

Full list of author information is available at the end of the article
}

(c) The Author(s). 2017 Open Access This article is distributed under the terms of the Creative Commons Attribution 4.0 International License (http://creativecommons.org/licenses/by/4.0/), which permits unrestricted use, distribution, and reproduction in any medium, provided you give appropriate credit to the original author(s) and the source, provide a link to the Creative Commons license, and indicate if changes were made. The Creative Commons Public Domain Dedication waiver (http://creativecommons.org/publicdomain/zero/1.0/) applies to the data made available in this article, unless otherwise stated. 


\section{Background}

Nicotiana attenuata, is a diploid wild tobacco native to the Great Basin desert of the United States with populations across Utah, Nevada, Arizona, Oregon, and California. This plant has adapted to an ecological niche defined by the post-fire environment, where soils tend to be nitrogenrich and biotic stresses are highly dynamic [1]. During the last decade, $N$. attenuata has been developed as a model organism to study plant-environment interactions in its native environment [2-6], and a large number of transcriptomic and metabolomic datasets have been generated with this plant. For example, more than 230 transcriptomic data from $N$. attenuata have been submitted to the NCBI GEO database. However, to efficiently analyze, explore and visualize such genome-wide metabolomic and transcriptomic data remain challenging for individual researchers. In particular, most of these data were not centralized and integrated. Recently, we sequenced and annotated the genomes of $N$. attenuata and its close relative $N$. obtusifolia [7], which provided an opportunity to create tools for centralizing, integrating and visualizing these omics data from this plant.

Specialized metabolites are of special importance in the defenses of plants, therefore, understanding their regulation and their evolutionary history are of central interests in plant biology. However, identifying genes involved in the biosynthesis of specialized metabolites remains difficult due to the large number of gene duplication events in plant genomes, and the structural diversity of the metabolites produced by plants. Recently, studies suggest that co-expression analysis is a powerful tool to rapidly identify genes involved in the biosynthesis of specialized metabolites, because many of these genes are often coexpressed [8]. However, such co-expression analysis often involves large amounts of data and remains difficult to handle for researchers who are not familiar with sophisticated statistics and lack programming skills.

Here, we present the Nicotiana attenuata Data Hub (NaDH, http://nadh.ice.mpg.de), a centralized publicly available platform for storing and integrating genomic, transcriptomic and metabolomic data from $N$. attenuata (Fig. 1). To provide user-friendly data analysis and visualization, we implemented tools from the Electronic Fluorescent Pictograph (eFP) browser, co-expression networks and the Interactive Tree Of Life (iTOL). Using the genes from the biosynthetic pathway of phenolamides as an example, we show that $\mathrm{NaDH}$ users can rapidly identify genes involved in specialized metabolites and make inferences on their evolution history.

\section{Construction and content}

\section{Genomic data}

The $\mathrm{NaDH}$ includes 33,449 and 27,911 predicted gene models from $N$. attenuata (release r2.0) and $N$. obtusifolia genomes (release r1.0), respectively. For comparative genomic analysis, additional gene sequences and structures from nine dicot plant genomes are also included in the database (Table 1). To provide functional annotations, the predicted enzyme commission (EC) identities, gene ontology (GO) terms, and protein domains are included.

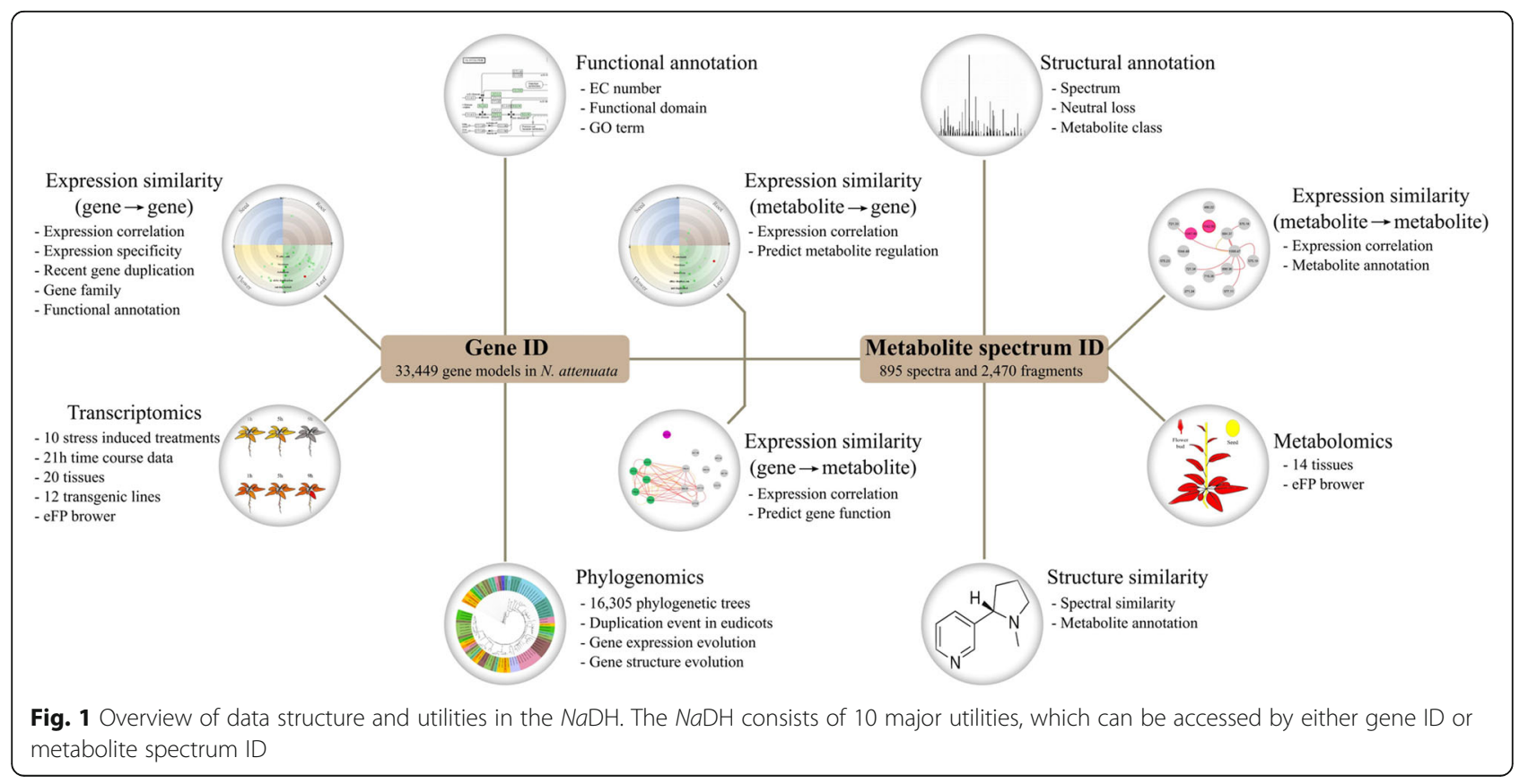


Table 1 Overview of included species for comparative genomics

\begin{tabular}{|c|c|c|c|c|}
\hline Species & Version & \# of genes & URL & Reference \\
\hline N. attenuata & r2.0 & 33,449 & http://nadh.ice.mpg.de/NaDH/download/ & {$[7]$} \\
\hline N. obtusifolia & r1.0 & 27,911 & http://nadh.ice.mpg.de/NaDH/download/ & {$[7]$} \\
\hline A. thaliana & TAIR 10 & 27,416 & http://phytozome.jgi.doe.gov/arabidopsis & {$[9,10]$} \\
\hline C. annuum & v2.0 & 35,336 & $\begin{array}{l}\text { http://peppersequence.genomics.cn/page } \\
\text { /species/download.jsp }\end{array}$ & [11] \\
\hline C. sativus & v1.0 & 21,503 & http://phytozome.jgi.doe.gov/cucumber & [12] \\
\hline M. guttatus & v2.0 & 28,140 & http://phytozome.jgi.doe.gov/mimulus & [13] \\
\hline P. trichocarpa & v3.0 & 41,335 & http://phytozome.jgi.doe.gov/poplar & [14] \\
\hline S. lycopersicum & ITAG2.3 & 34,727 & http://phytozome.jgi.doe.gov/tomato & {$[15]$} \\
\hline S. melongena & V2.5.1 & 42,035 & ftp://ftp.kazusa.or.jp/pub/eggplant/ & {$[16]$} \\
\hline S. tuberosum & v3.4 & 35,119 & http://phytozome.jgi.doe.gov/potato & {$[17]$} \\
\hline V. vinifera & Genoscope.12X & 26,346 & http://phytozome.jgi.doe.gov/grape & [18] \\
\hline
\end{tabular}

\section{Gene families and phylogeny}

The $\mathrm{NaDH}$ includes 23,340 homologous groups constructed based on protein coding sequences from 11 eudicot species (Table 1). PhyML was used to construct phylogenetic trees with high confidence from these homologous groups that contain more than two genes. In total, 16,305 trees containing 255,404 genes (of which 28,610 are from $N$. attenuata) are included in the $\mathrm{NaDH}$. In addition, 81,859 gene duplication events detected from high confidence phylogenetic trees (approximate Bayes branch supports of greater than 0.9 for the target node and its two child nodes) using the species-overlapping algorithm implemented in Notung-2.6 $[19,20]$ are also included in the database. The majority of gene duplication events in $N$. attenuata are found at the Solanaceae branch (Table 2), consistent with the observation that species of Solanaceae share a wholegenome triplication event.

\section{Transcriptomic data}

The $\mathrm{NaDH}$ contains expression profiles from both RNAseq and microarray datasets [21-23]. For the RNA-seq datasets (Illumina HiSeq 2000, pair-end sequencing, NCBI accession number: PRJNA317743), the expression level

Table 2 The number of detected duplication events in $\mathrm{N}$. attenuata

\begin{tabular}{ll}
\hline Duplication time & \# of duplications \\
\hline N. attenuata specific & 3,929 \\
Shared among Nicotiana spp. & 2,577 \\
Shared among Solanaceae & 6,760 \\
Shared with M. guttatus & 240 \\
Shared among core eudicots & 8,548 \\
Total & 22,054 \\
\hline
\end{tabular}

A large number of duplication events is shared among all Solanaceae, which supports a shared whole-genome triplication event (transcript per million, TPM) [24] of each gene from different tissues sampled from leaves, seeds, roots, stems and flowers are included (Table 3). In total, 21,970 genes were expressed in at least one tissue (TPM greater than 5). Roots contain the largest number of expressed genes (Table 3). For the microarray dataset, 222 microarrays (based on Agilent platform: GPL13527) from N. attenuata leaves, roots and flowers are included. The probes of this microarray platform were mapped to the $N$. attenuata genome and the uniquely mapped probes were annotated according to gene predictions. In total, this microarray platform contains the expression profiles of 27,374 predicted $N$. attenuata genes. The microarray datasets are organized according to their corresponding experiments and the detailed information on the genotypes, developmental stages, treatments of the plants that provided the samples (Additional file 1) are provided.

\section{Metabolomic data}

Metabolomic data from 14 isolated tissues of $N$. attenuata growing under controlled conditions in glasshouse were curated. This includes a pool of all non-senescing rosette leaves, combined lower, middle and higher segments of the stem, the complete root system, dried seeds, complete floral buds of $8 \mathrm{~mm}$ length, complete sepal ring, the nectary, the ovary (not including the nectary), the style, anthers, filaments (not including anthers), and the corolla tube and limb, collected at anthesis. Pools of $100 \mathrm{mg}$ tissues were extracted using $80 \%$ methanol. Independent extractions were also conducted with $20 \%$ methanol. Samples were analyzed using UHPLC-ESI/qTOF-MS in positive ion mode. MS/MS data collection was achieved via a previously-described pipeline [25] and 895 reconstructed MS/MS spectra were obtained [26]. This MS/ MS dataset has also been deposited in the EMBL EBI open metabolomics database MetaboLights: www.ebi. ac.uk (accession no. MTBLS335). 
Table 3 Overview of RNA-Seq data

\begin{tabular}{|c|c|c|c|c|}
\hline $\begin{array}{l}\text { Library ID/ } \\
\text { SRA ID }\end{array}$ & Tissue & Treatment/development stage & $\begin{array}{l}\text { \# of expressed } \\
\text { genes }\end{array}$ & Additional note on sampling procedure \\
\hline $\begin{array}{l}\text { NA1498ROT } \\
\text { SRX1804895 }\end{array}$ & Root & $\begin{array}{l}\text { Rosette stage plants, treated with } 5 \mu \mathrm{L} \text { 1:1 } \\
\text { diluted } M \text {. sexta oral secretion three times } \\
\text { in leaves }\end{array}$ & 15,499 & $\begin{array}{l}\text { Roots of rosette stage plants that were treated three times on } \\
\text { leaves were collected for RNA extraction. The treatments were } \\
\text { performed at } 10 \text { am and } 6 \text { pm on the day before sampling and } \\
10 \text { am on the day of sampling. Samples were collected at } 11 \mathrm{am} \text {. }\end{array}$ \\
\hline $\begin{array}{l}\text { NA1500LET } \\
\text { SRX1804896 }\end{array}$ & Leaf & $\begin{array}{l}\text { Rosette stage plants, treated with } 5 \mu \mathrm{L} \text { 1:1 } \\
\text { diluted } M \text {. sexta oral secretion three times } \\
\text { in leaves }\end{array}$ & 12,179 & $\begin{array}{l}\text { Local leaves of rosette stage plants that were treated three times } \\
\text { on leaves were collected for RNA extraction. The treatments were } \\
\text { performed at } 10 \text { am, } 6 \text { pm on the day before sampling and } 10 \text { am } \\
\text { on the day of sampling. Samples were collected at } 11 \text { am. }\end{array}$ \\
\hline $\begin{array}{l}\text { NA1717LEC } \\
\text { SRX1804554 }\end{array}$ & Leaf & Rosette stage plants, no treatment & 11,840 & $\begin{array}{l}\text { Rosette stage leaves were collected for RNA extraction. Samples } \\
\text { were collected at } 11 \mathrm{am} \text {. }\end{array}$ \\
\hline $\begin{array}{l}\text { NA1504STT } \\
\text { SRX1804900 }\end{array}$ & Stem & $\begin{array}{l}\text { Rosette stage plants, treated with } 5 \mu \mathrm{L} \text { 1:1 } \\
\text { diluted } M \text {. sexta oral secretion three times } \\
\text { in leaves }\end{array}$ & 14,682 & $\begin{array}{l}\text { Stems of rosette stage plants that were treated three times on } \\
\text { leaves were collected for RNA extraction. The treatments were } \\
\text { performed at } 10 \mathrm{am}, 6 \mathrm{pm} \text { on the day before sampling and } 10 \\
\mathrm{am} \text { on the day of sampling. Samples were collected at } 11 \mathrm{am} \text {. }\end{array}$ \\
\hline $\begin{array}{l}\text { NA1505COE } \\
\text { SRX1804901 }\end{array}$ & Corolla & Early developmental stage, no treatment & 13,662 & $\begin{array}{l}\text { Samples were collected in the afternoon, } 60 \text { samples were } \\
\text { pooled. }\end{array}$ \\
\hline $\begin{array}{l}\text { NA1515COL } \\
\text { SRX1804913 }\end{array}$ & Corolla & Late developmental stage, no treatment & 13,486 & $\begin{array}{l}\text { Samples were collected at } 6 \mathrm{pm} \text { (open flowers) and } 9 \text { am (closed } \\
\text { flower after opening), 4-10 samples were pooled. }\end{array}$ \\
\hline $\begin{array}{l}\text { NA1506STI } \\
\text { SRX1804902 }\end{array}$ & Stigma & Mature stigma, no treatment & 14,485 & $\begin{array}{l}\text { Stigma samples were collected in the afternoon, } 40 \text { samples were } \\
\text { pooled. }\end{array}$ \\
\hline $\begin{array}{l}\text { NA1507POL } \\
\text { SRX1804903 }\end{array}$ & $\begin{array}{l}\text { Pollen } \\
\text { tube }\end{array}$ & No treatment & 3,490 & Pollen tubes were pooled. \\
\hline $\begin{array}{l}\text { NA1508SNP } \\
\text { SRX1804904 }\end{array}$ & Style & Mature style without pollination & 13,492 & $\begin{array}{l}\text { Styles were collected at } 7 \text { am, anthers were removed one day } \\
\text { before, and } 50 \text { samples were pooled. }\end{array}$ \\
\hline $\begin{array}{l}\text { NA1509STO } \\
\text { SRX1804905 }\end{array}$ & Style & $\begin{array}{l}\text { Mature style, pollinated with pollens } \\
\text { from different genotype }\end{array}$ & 13,365 & $\begin{array}{l}\text { Styles were collected at two hours after pollination, at } 7 \mathrm{am} \text {. } \\
\text { Anthers were removed one day before, and } 30 \text { samples were } \\
\text { pooled. }\end{array}$ \\
\hline $\begin{array}{l}\text { NA1510STS } \\
\text { SRX1804906 }\end{array}$ & Style & Mature style, self-pollinated & 13,533 & $\begin{array}{l}\text { Styles were collected at two hours after pollination, at } 7 \mathrm{am} \text {. } \\
\text { Anthers were removed one day before, and } 30 \text { samples were } \\
\text { pooled. }\end{array}$ \\
\hline $\begin{array}{l}\text { NA1511NEC } \\
\text { SRX1804907 }\end{array}$ & Nectary & Mature nectary, no treatment & 12,928 & $\begin{array}{l}\text { Samples were collected in the afternoon, } 60 \text { samples were } \\
\text { pooled. }\end{array}$ \\
\hline $\begin{array}{l}\text { NA1512ANT } \\
\text { SRX1804908 }\end{array}$ & Anther & Mature anther no treatment & 11,550 & $\begin{array}{l}\text { Samples were collected in the afternoon, } 60 \text { samples were } \\
\text { pooled. }\end{array}$ \\
\hline $\begin{array}{l}\text { NA15130VA } \\
\text { SRX1804909 }\end{array}$ & Ovary & Mature ovary, no treatment & 13,960 & $\begin{array}{l}\text { Samples were collected in the afternoon, } 60 \text { samples were } \\
\text { pooled. }\end{array}$ \\
\hline $\begin{array}{l}\text { NA1514PED } \\
\text { SRX1804910 }\end{array}$ & Pedicel & Mature pedicel, no treatment & 14,550 & $\begin{array}{l}\text { Samples collected at } 9 \text { am (heading down) and } 4 \text { pm (heading } \\
\text { up) were pooled. }\end{array}$ \\
\hline $\begin{array}{l}\text { NA1516OFL } \\
\text { SRX1804911 }\end{array}$ & Flower & Fully opened flowers, no treatment & 14,390 & $\begin{array}{l}\text { Both morning }(7 \mathrm{am}) \text { and evening }(6 \mathrm{pm}) \text { flowers were collected, } \\
1 \text { sample of each were pooled. }\end{array}$ \\
\hline $\begin{array}{l}\text { NA1517FLB } \\
\text { SRX1804912 }\end{array}$ & $\begin{array}{l}\text { Flower } \\
\text { bud }\end{array}$ & $\begin{array}{l}\text { Two early developmental stages of } \\
\text { flowers, no treatment }\end{array}$ & 14,543 & $\begin{array}{l}\text { Samples were collected at } 6 \text { pm, } 1 \text { bud and } 1 \text { middle stage } \\
\text { flower were collected. Sepals were removed from the samples. }\end{array}$ \\
\hline $\begin{array}{l}\text { NA1501SES } \\
\text { SRX1804897 }\end{array}$ & Seed & Treated with liquid smoke & 9,227 & $\begin{array}{l}100 \mathrm{mg} \text { seeds treated with 1:50 diluted liquid smoke solution for } \\
\text { 9-15 min were used for RNA extraction. }\end{array}$ \\
\hline $\begin{array}{l}\text { NA1502SEW } \\
\text { SRX1804898 }\end{array}$ & Seed & Treated with water & 8,872 & $\begin{array}{l}100 \mathrm{mg} \text { seeds treated with water for 9-15 min were used for total } \\
\text { RNA extraction. }\end{array}$ \\
\hline $\begin{array}{l}\text { NA1503SED } \\
\text { SRX1804899 }\end{array}$ & Seed & Dry seeds & 8,681 & 100 mg dried seeds directly used for total RNA extraction. \\
\hline
\end{tabular}

The raw reads information and methods used for generating these data are available under NCBI accession number PRJNA317743

\section{Gene-to-gene co-expression}

To facilitate the identification of co-regulated genes in $N$. attenuata, we calculated the pairwise expression correlation co-efficiency based on RNA-seq data from 20 different tissues using three different methods:
Gini, Spearman and Pearson [27]. In total, 15,216 informative genes (with TPM greater than 5 in at least one tissue and a variance greater than 1) were used and gene pairs with absolute expression similarity greater than 0.65 were considered for the final dataset. 
All data are stored in $\mathrm{NaDH}$ and can be visualized in a network graph.

\begin{abstract}
Metabolite-to-metabolite co-expression
Metabolite-to-metabolite tissue associations were calculated using Ochiai similarity based on binary metabolite dataset (containing 14 tissue vectors), with a cutoff of 2 on the ZMAD transformed values [28]. The metabolite-tometabolite pairwise associations were calculated across the dataset by comparing each metabolite spectrum with the other metabolite spectra [26]. All data are stored in the underlying database for fast accessing under the utilities of $\mathrm{NaDH}$.
\end{abstract}

\section{Gene-to-metabolite co-expression}

Gene-to-metabolite tissue associations were calculated using Ochiai similarity with binary gene and metabolite data (presence and absence) generated from 12 shared tissues between the transcriptome dataset and the metabolome dataset (a cutoff of transcriptome dataset is ZMAD transformed TPM greater than 3 and a cutoff of metabolome dataset is ZMAD transformed value greater than 2). Gene expression was centered by median and medianabsolute-deviation (MAD) to obtain a relative expression level [29]. In total, 23,075 genes and 895 metabolite spectra with expression levels above the threshold were used for the network constructions [26]. The pairwise correlations were calculated using Ochiai correlations based on the transformed binary values [28] and only Ochiai correlation coefficient (occ) greater than 0.3 were considered for the final dataset. The resulting network is based on a correlation matrix between 18,046 genes and 887 metabolite spectra.

\section{Metabolite structure similarity}

Metabolite structure similarity was calculated from pairwise MS/MS alignments based on spectral fragment similarity and common neutral losses similarity (NL). A standard normalized dot product (NDP), also referred to as the cosine correlation method for spectral comparison, was applied for the calculations of spectral fragment similarity. The NL-based similarity between individual MS/MS was implemented using a list of 52 neutral losses (NLs) commonly encountered during tandem MS fragmentation as well as more specific ones that had been previously annotated for MS/MS spectra of $N$. attenuata secondary metabolite classes [25].

\section{Database architecture and implementation details}

An overview of the $\mathrm{NaDH}$ database architecture is shown in Fig. 1. All data are connected to the gene and metabolite. The data storage function was implemented using the open-source relational management system MySQL to store all data except the genome and gene sequence information. The website was developed using Kohana - an open source, object-oriented model-view-controller (MVC) web framework (https://kohanaframework.org/). The unique filesystem design of the Kohana web framework allows a modular design of all $\mathrm{NaDH}$ features and enables easy implementations of new functions in the future. The visualization of gene and metabolites expression was implemented by a modified version of the eFP Browser [30]. For interactive visualization of the different co-expression networks, we implemented the open-source graph visualization tool Cytoscape.js (https://github.com/cytoscape/cytoscape.js).

\section{Utility and discussion}

\section{Search functions}

Search functions are implemented for finding genes and metabolites. Genes of $N$. attenuata can be searched by name, functional annotation (InterPro domain, EC number, Gene Ontology identifier), orthologous genes in other species and sequence similarity based on BLAST. Metabolite spectra and fragments can be searched by name, metabolite class and measurements $(\mathrm{m} / \mathrm{z}$ value, retention time). In both scenarios, a table summarizes information of the corresponding genes or metabolite spectra, and guides users to downstream analysis.

\section{Gene-to-gene co-expression analysis}

This function can be used to understand the regulatory mechanisms and predict putative functions of genes. The input is the identifier of a gene, and the outputs are genes co-expressed with the input gene above the user defined threshold (correlation coefficient) and this is presented in both an interactive network graph and table formats. In the resulting co-expression network graph, each node represents a co-expressed gene, radiating position of the node represents the most recent duplication events it has experienced and clock-wise position of the node represents the region with the highest expression among four tissues (leaves, roots, flower buds, and seeds) and relative tissue specificity. The resulting table shows more detailed functional annotation of each node. Figure $2 \mathrm{a}$ shows an example output for the transcription factor NaMYB8 (NIATv7_g41919).

\section{Metabolite-to-metabolite co-expression analysis}

This function can be used to find co-regulated metabolite spectra, which might indicate co-occurrence in biosynthetic pathways and signal cascades. The input of this function is the identifier of a metabolite spectrum of interest, and all co-expressed metabolite spectra above the user-defined threshold and the results are presented in co-expression network graph and table formats. In the co-expression network, each node represents a metabolite spectrum, the color of 
a Gene-gene co-expression

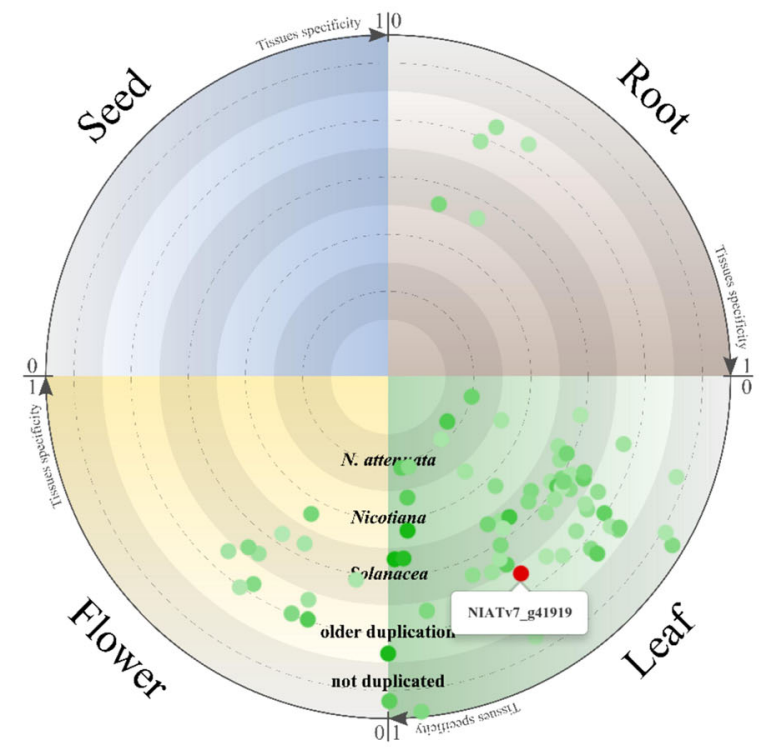

input gene: $N a M Y B 8$ similarity: $\geq 0.9$

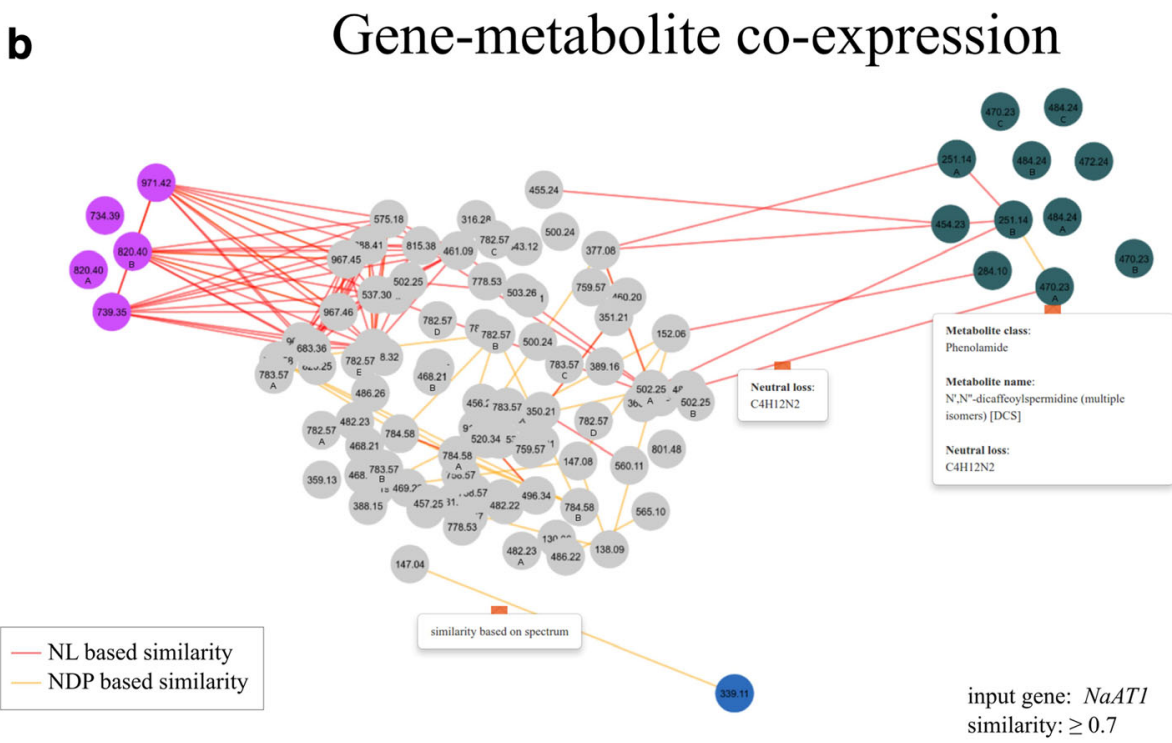

Fig. 2 Examples of visualization on co-expressed genes and metabolites. a Genes that are co-expressed with a transcription factor (TF) NaMYB8 (NIATV7_g41919) (red). Each node represents a co-expressed gene, radiating position of the node represents the most recent duplication events it has experienced and clock-wise position of the node represents the highest expression among four tissues and relative tissue specificity. $\mathbf{b}$ Metabolite spectra that are co-expressed with NaAT1 (NIATV7_g11614), a gene from phenolamides pathway. Color indicate different functional classes of metabolite spectra: dark green: phenolamides; pink: different 17-hydrogeranyllinalool diterpene glycosides; blue: quinate conjugates; grey: not annotated metabolite spectra. Node number shows the $\mathrm{m} / \mathrm{z}$ value of the metabolite spectrum and letters refers to different isotopes. Edges indicate structure similarities among metabolite spectra: yellow: NDP based similarity, red: NL based similarity. NDP was calculated based on shared fragments and NL was calculated based on shared neutral losses

the nodes represents the annotated class of the corresponding metabolite spectrum, and the edge represents the structural similarity between two nodes: a yellow edge for NDP and red edge for NL. The network can be re-arranged based on expression similarity values or annotated metabolite classes.

\section{Gene-to-metabolite co-expression analysis}

Co-expression between gene and metabolite can be used to both infer putative functions of the genes and to identify candidate biosynthetic pathways of the metabolites [31-34]. In the $\mathrm{NaDH}$, we provide a function to find bidirectional searches for co-expressed genes and metabolite 
spectra. For searching metabolite spectra that are coexpressed with a gene of interest, the input is an identifier of the gene and the output is a metabolite spectra network with each node representing a metabolite spectrum and each edge representing the structural similarity between two metabolite spectra. In order to search for genes that co-express with a metabolite spectrum of interest, the input is an identifier of the metabolite spectrum and the output is the gene co-expression network with each node representing a gene and the position of the node representing the duplication history and expression (similar to gene-gene co-expression network graph). Figure $2 \mathrm{~b}$ shows the co-expressed metabolite spectra for the gene NaAT1 (NIATv7_g11614).

\section{Phylogenetic analysis}

In the $\mathrm{NaDH}$, a phylogenetic tree can be directly uploaded and visualized with iTOL $[35,36]$. The input is an identifier of the gene of interest, and the output is a phylogenetic tree that integrates the expression of $N$. attenuata genes among 20 different tissues. In addition, the intron-exon structures were also integrated with the phylogenetic tree to provide further information on the evolutionary history of the gene. Figure $3 \mathrm{c}$ shows an example of the output for the gene DH29 of the phenolamides pathway.

\section{Expression visualization}

The expression of genes and metabolites can be visualized via a modified version of the eFP Browser developed by Nicholas J. Provart et al [30]. The input is either the identifier of a gene (or a probe ID from the microarray) or metabolite spectrum of interest and the output is the expression of the gene (or probe) or precursor of a metabolite spectrum mapped to each tissue or treatment, respectively. The expression levels of the gene are shown as a heatmap with yellow and red colors indicate low and high expression, respectively. The binary expression of the precursor of a metabolite spectrum is shown as a heatmap with red and yellow colors indicate expressed and not expressed, respectively. Figure $3 \mathrm{a}$ and $\mathrm{b}$ show an example output for a gene and metabolite in the eFP Browser, respectively. The expression values are also provided as a table or bar chart for user-specific analysis. In addition, we also implemented a function to compare and visualize the expression of multiple genes and precursors of metabolite spectra among different tissues.

\section{Example analysis}

The evolution and diversity of specialized metabolites in plants are largely shaped by gene duplication events [37]. Consequently, to find which of the duplicated copies are involved in the biosynthesis and regulation of specific secondary metabolites is challenging. Using the above-described utilities in the $\mathrm{NaDH}$ and genes known to be involved in phenolamides biosynthetic pathway as an example, we show that the integration of geneto-gene, gene-to-metabolite, metabolite-to-metabolite and gene duplication history can help to identify genes that are involved in specialized metabolites in the genus Nicotiana.

Phenolamides, a group of diverse metabolites abundant in many plant reproductive organs, are rapidly induced after herbivore attack in vegetative tissues of several Solanaceae species and play an important role as induced chemical defenses. The biosynthesis of phenolamides originates from the main phenylpropanoid pathway via $\mathrm{N}$-acyltransferase-dependent conjugation to polyamines or aryl monoamines (Fig. 4) [38, 39]. Similar to the biosynthetic pathways of many other secondary metabolites, genes involved in the phenylpropanoid pathway contain multiple copies (Fig. 4). Because several genes involved in the regulation and biosynthesis of phenolamides have been functionally characterized in $N$. attenuata, this group of metabolites provides an ideal example to test the utility of the $\mathrm{NaDH}$.

One of the key components that regulates the biosynthesis of phenolamides in $N$. attenuata is the R2R3-MYB transcription factor, NaMYB8 (NIATv7_g41919) [40]. We first searched for all genes that were co-expressed with NaMYB8 with a cutoff with a gini correlation coefficient (gcc) greater than 0.7, which resulted in 2,620 coexpressed genes. Among these genes, we searched for homologs that are putatively involved in biosynthetic steps of the main phenylpropanoid pathway. Although in each step, several copies were found in $N$. attenuata, only one or two copies were co-expressed with NaMYB8. Among them, functional characterization using virus-induced gene silencing (VIGS) revealed that AT1, CV86 and DH29 are indeed involved in the biosynthesis of herbivoreinduced phenolamides, such as caffeoylputrescine (CP) and $N, N$,-dicaffeoylspermidine (DCS), which function as anti-herbivore chemical defenses [40]. The duplication history of these genes also showed that most of the recent duplications of these genes were from the Solanaceae branch, suggesting the whole genome triplication event of the Solanaceae contributed to the evolution of herbivoreinduced phenolamides in Nicotiana. Additional coexpression analysis of gene-metabolite and metabolitemetabolite associations showed that the key metabolites (phenylalanine, MCS, CP and DCS) and genes (NaPAL, $\mathrm{NaC} 3 \mathrm{H}, \mathrm{NaDH} 29$ ) from the pathway can be retrieved by searching highly co-expressed genes and metabolites (Fig. 4b). Although such co-expression analysis can only be used for the metabolites that are synthesized in the tissues that they accumulate in, these results suggest that using the utilities implemented in the $\mathrm{NaDH}$, users can rapidly identify co-expressed genes and metabolites that are involved in the same pathway. 


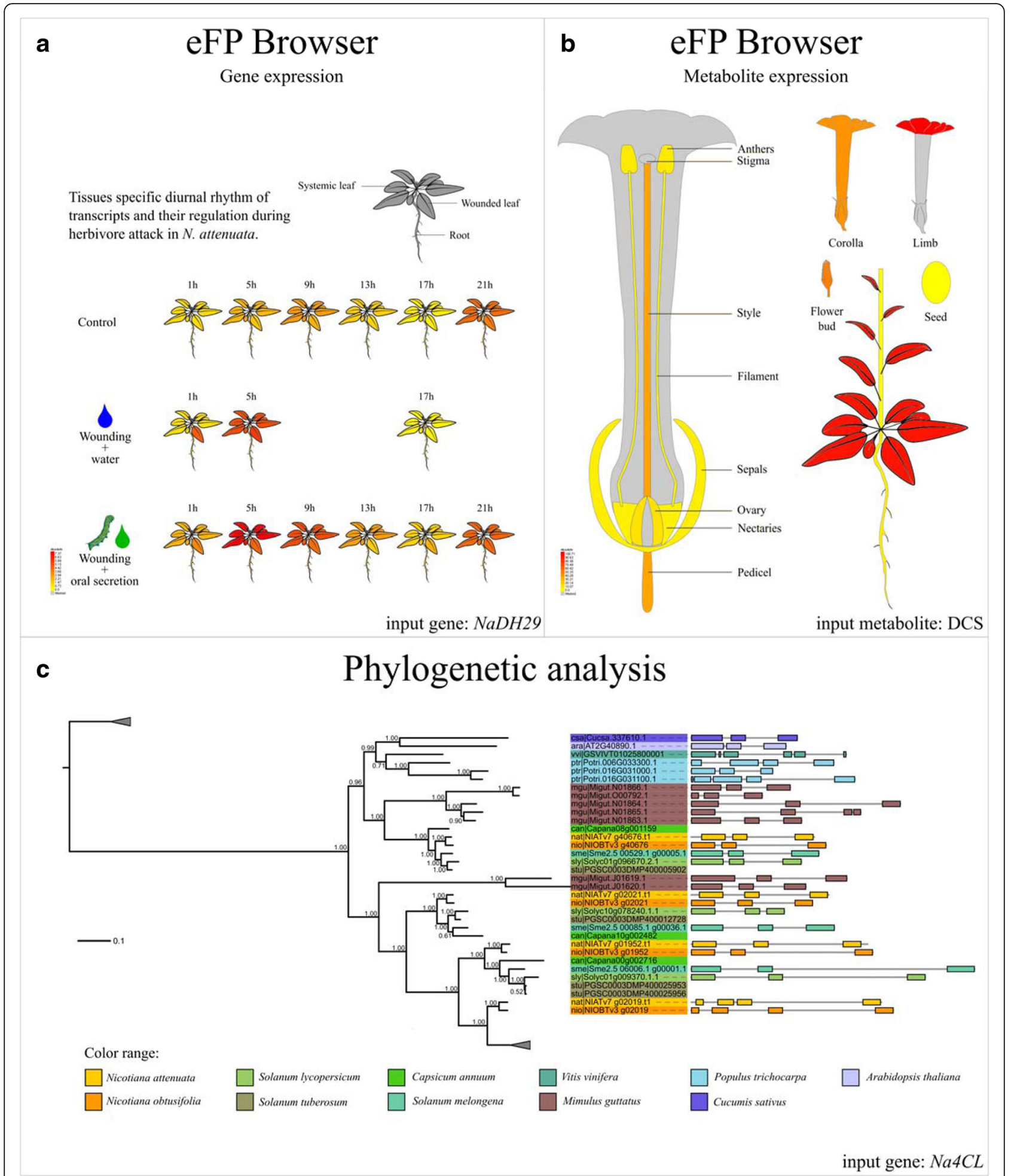

Fig. 3 Example of visualizing gene expression and evolution. a Expression of NaDH29 (NIATV7_g06682) in leaves and roots of control or wounding or M. sexta oral secretion induced plants. b Presence and absence of $N^{\prime}, N^{\prime \prime}$-dicaffeoylspermidine (DCS) [m/z: 470.2284287, retention time: 395.616992] different N. attenuata tissues. c Phylogenetic tree of $4 C L$ gene family visualized using iTOL. Gene structure of each gene is shown on the right side. Colors refer to different species 


\section{a}

\section{Co-expressed genes with $\mathrm{NaMYB8}$}

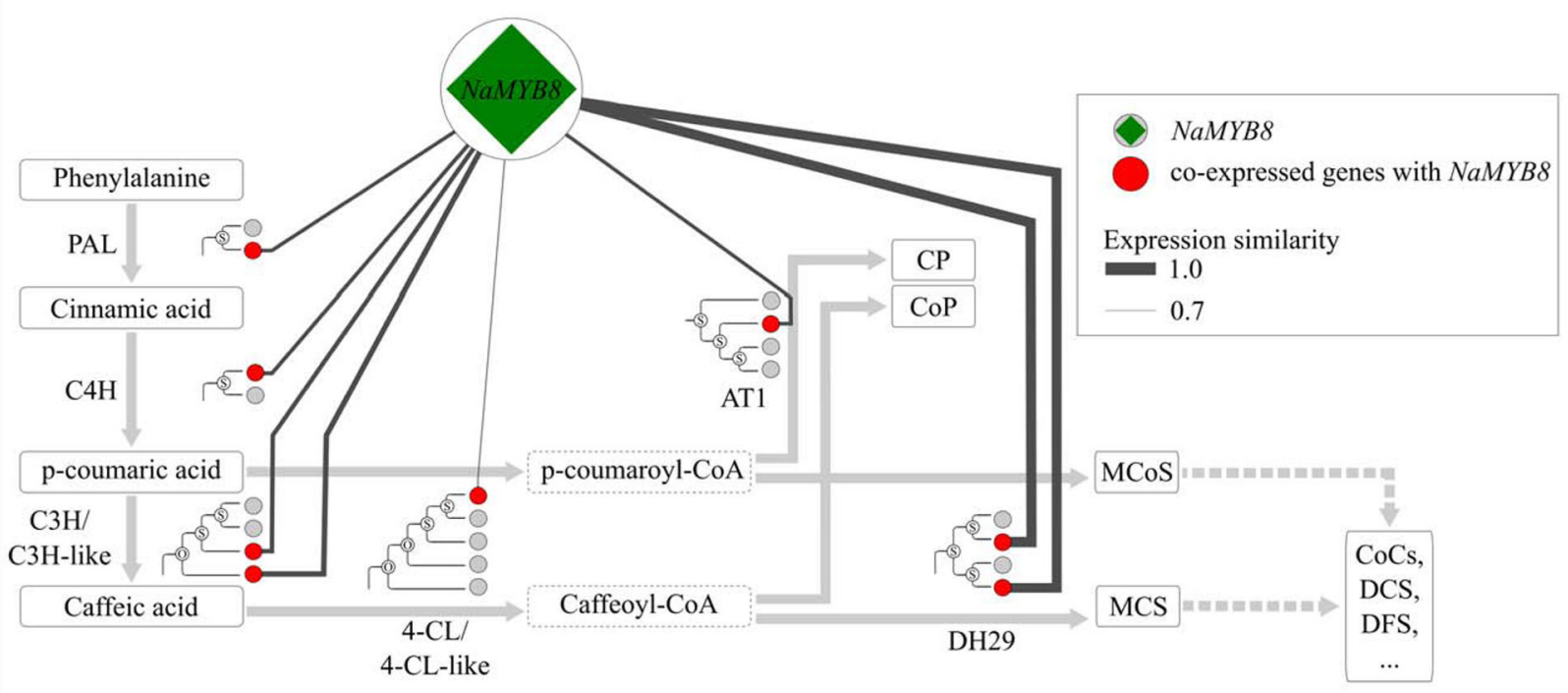

\section{b Co-expressed metabolites and genes in the phenolamides pathway}

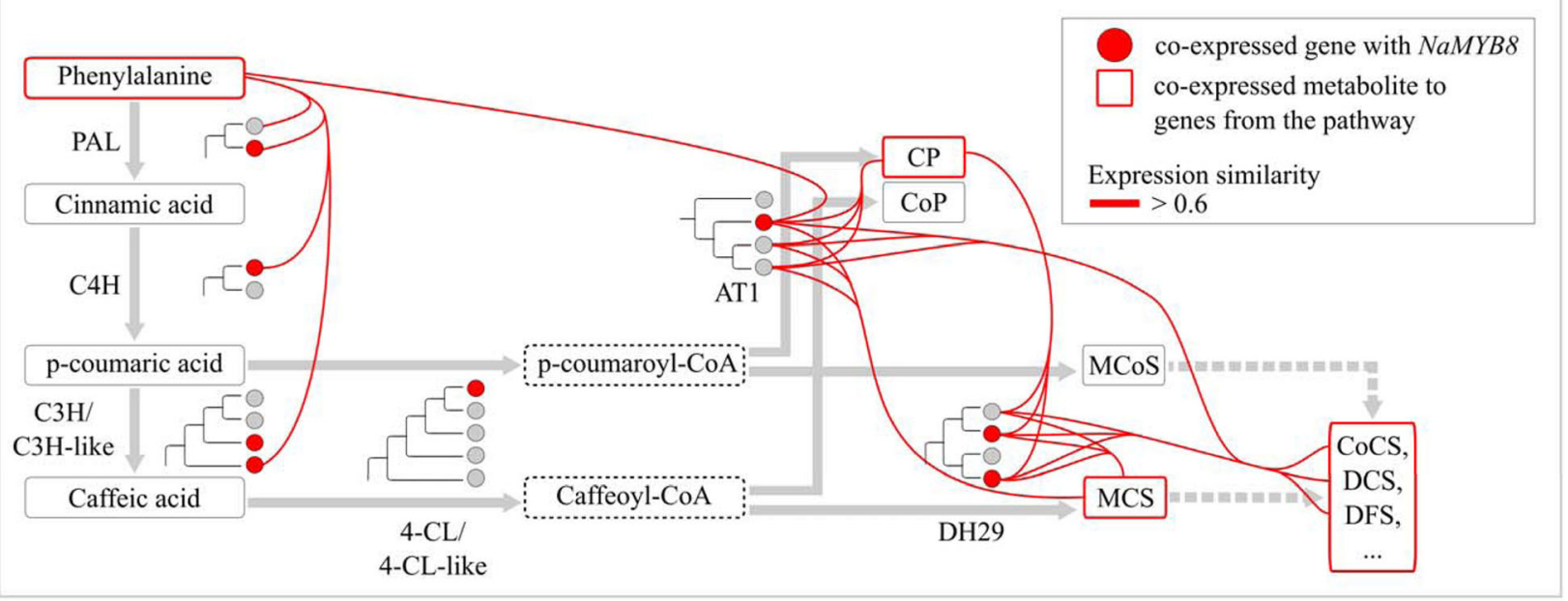

Fig. 4 Co-expressed genes and metabolite spectra of the phenolamides pathway. a Genes co-expressed with NaMYB8 (NIATV7_g41919). Each circle indicates one gene and the tree structure visualizes their phylogenetic history and the age of the duplication events: N: Nicotiana specific; S: Solanaceae specific; O: older duplication. The red color indicates that the gene is correlated with NaMYB8. The thickness of the black lines connecting NaMYB8 with other genes indicates the expression correlation coefficient. PAL: Phenylalanine ammonia-lyase; $\mathrm{C} 4 \mathrm{H}$ : cinnamate-4-hydroxylase; $\mathrm{C} 3 \mathrm{H}$ : coumarate-3-hydroxylase; 4CL: 4-coumarate coenzyme A ligase. b Co-expression of metabolites and genes from the phenolamides pathway. CP: N-caffeoylputrescine, CoP: N-coumaroylputrescine, MCOS: N-coumarylspermidine, MCS: N-caffeoylspermidine, CoCS: N-coumaryl, caffeoyl spermidine, DCS: $N^{\prime}, N^{\prime \prime}$-dicaffeoylspermidine, DFS: $N^{\prime}, N^{\prime \prime}$-di-feruloyl-spermidine, dashed line: unknown reaction, dashed box: metabolite not measurable with used mass spectrometry method. Red lines indicate correlation coefficient higher than 0.6

\section{Conclusion}

We present the $\mathrm{NaDH}$, which integrates genomic, transcriptomic, and metabolomic data in N. attenuata and provides useful tools for the interactive visualization of gene expression divergence and gene duplication history. Additional tools for finding coexpressed genes and metabolites can facilitate rapid gene discovery for specialized metabolites in $N$. attenuata and infer their evolutionary paths. Since the most of genome-wide features are shared among the genus Nicotiana, the $\mathrm{NaDH}$ can also be used to explore the function and evolution of genes in other Nicotiana species.

\section{Availability of data and materials}

The datasets generated and/or analysed during the current study are available in $\mathrm{NaDH}$ (http://nadh.ice.mpg.de/ $\mathrm{NaDH} /$ ). 


\section{Additional file}

Additional file 1: Overview of microarray datasets that can be visualized via the eFP browser in $\mathrm{NaDH}$. Different unique experiments are included that consist of different genotypes, treatments and time points. EV: empty vector; WT: wild type; W: induced by water; OS: induced by $M$. sexta oral secretion; VIGS: virus-induced gene silencing; GLV: green leaf volatile; VOC: volatile organic compound. (DOCX 17 kb)

\section{Abbreviations}

GLV: Green leaf volatiles; NDP: Normalized dot product; NL: Neutral losses; OS: M. sexta oral secretion; TPM: Transcripts per million; VIGS: Virus-induced gene silencing; VOC: Volatile organic compound; WT: Wild type

\section{Acknowledgments}

We thank all members of the Molecular Ecology Department, Max Planck Institute for Chemical Ecology for fruitful discussions and valuable comments. We thank Martin Niebergall for providing technique support on setting up the public database and Meret Huber for constructive suggestions on the manuscript.

\section{Funding}

The work was supported by Swiss National Science Foundation (project number: PEBZP3-142886 to SX), the Marie Curie Intra-European Fellowship (IEF) (Project Number: 328935 to SX) and the Max Planck Society.

\section{Competing interests}

The authors declare that they have no competing interests.

\section{Authors' contributions}

TB and SX designed and developed the database system. TB, ZL and SX generated gene annotations and analyzed data. EG and DL performed the mass spectrometry analysis, inferred tissue-preferentiality of expression for metabolites and developed the gene-to-metabolite co-expression and metabolite similarity analysis. SX and TB wrote the manuscript. ITB provided the -omic data organized by the $\mathrm{NaDH}$. All authors have read and approved the final manuscript.

\section{Consent for publication}

Not applicable.

\section{Ethics approval and consent to participate}

Not applicable.

\section{Author details}

${ }^{1}$ Department of Molecular Ecology, Max Planck Institute for Chemical Ecology, Hans-Knöll-Straße 8, D-07745 Jena, Germany. ${ }^{2}$ Centre for Organismal Studies, Heidelberg University, Im Neuenheimer Feld 360, Heidelberg D-69120, Germany.

Received: 30 June 2016 Accepted: 23 December 2016

Published online: 13 January 2017

\section{References}

1. Nelson DC, Flematti GR, Ghisalberti EL, Dixon KW, Smith SM. Regulation of seed germination and seedling growth by chemical signals from burning vegetation. Annu Rev Plant Biol. 2012;63:107-30.

2. Schuman MC, Barthel K, Baldwin IT. Herbivory-induced volatiles function as defenses increasing fitness of the native plant Nicotiana attenuata in nature. eLife. 2012;2012:1-29.

3. Dinh ST, Baldwin IT, Galis I. The HERBIVORE ELICITOR-REGULATED1 gene enhances abscisic acid levels and defenses against herbivores in Nicotiana attenuata plants. Plant Physiol. 2013;162:2106-24

4. Zhang L, Oh Y, Li H, Baldwin IT, Galis I. Alternative oxidase in resistance to biotic stresses: Nicotiana attenuata AOX contributes to resistance to a pathogen and a piercing-sucking insect but not Manduca sexta larvae. Plant Physiol. 2012:160:1453-67.

5. Baldwin IT, Staszak-Kozinski L, Davidson R. Up in smoke: I. Smoke-derived germination cues for postfire annual, Nicotiana attenuata torr. Ex. Watson. J Chem Ecol. 1987;20:2345-71.
6. Baldwin IT. An ecologically motivated analysis of plant-herbivore interactions in native tobacco. Plant Physiol. 2001;127:1449-58.

7. Xu S, Brockmöller T, Navarro-Quezada A, Kuhl H, Gase K, Ling Z, et al. Wild tobacco genomes and the evolution of nicotine production. Submitted.

8. Kleessen S, Klie S, Nikoloski Z. Data integration through proximity-based networks provides biological principles of organization across scales. Plant Cell. 2013;25:1917-27.

9. Swarbreck D, Wilks C, Lamesch P, Berardini TZ, Garcia-Hernandez M, Foerster H, et al. The Arabidopsis Information Resource (TAIR): gene structure and function annotation. Nucleic Acids Res. 2008;36:D1009-14.

10. Lamesch P, Berardini TZ, Li D, Swarbreck D, Wilks C, Sasidharan R, et al. The Arabidopsis Information Resource (TAIR): improved gene annotation and new tools. Nucleic Acids Res. 2012:40:D1202-10.

11. Qin C, Yu C, Shen Y, Fang X, Chen L, Min J, et al. Whole-genome sequencing of cultivated and wild peppers provides insights into Capsicum domestication and specialization. Proc Natl Acad Sci U S A. 2014;111:513540.

12. Huang S, Li R, Zhang Z, Li L, Gu X, Fan W, et al. The genome of the cucumber, Cucumis sativus L. Nat Genet. 2009:41:1275-81.

13. Hellsten U, Wright KM, Jenkins J, Shu S, Yuan Y, Wessler SR, et al. Finescale variation in meiotic recombination in Mimulus inferred from population shotgun sequencing. Proc Natl Acad Sci U S A. 2013;110: 19478-82.

14. Tuskan G a, Difazio S, Jansson S, Bohlmann J, Grigoriev I, Hellsten U, et al. The genome of black cottonwood, Populus trichocarpa (Torr. \& Gray). Science. 2006; 313:1596-604

15. Tomato T, Consortium G. The tomato genome sequence provides insights into fleshy fruit evolution. Nature. 2012;485:635-41.

16. Hirakawa H, Shirasawa K, Miyatake K, Nunome T, Negoro S, Ohyama A, et al. Draft genome sequence of eggplant (Solanum melongena L.): the representative Solanum species indigenous to the old world. DNA Res. 2014;21:649-60.

17. Xu X, Pan S, Cheng S, Zhang B, Mu D, Ni P, et al. Genome sequence and analysis of the tuber crop potato. Nature. 2011:475:189-95.

18. Jaillon O, Aury J-M, Noel B, Policriti A, Clepet C, Casagrande A, et al. The grapevine genome sequence suggests ancestral hexaploidization in major angiosperm phyla. Nature. 2007;449:463-7.

19. Chen K, Durand D, Farach-Colton M. NOTUNG: a program for dating gene duplications and optimizing gene family trees. J Comput Biol. 2000;7:429_ 47.

20. Durand D, Halldórsson BV, Vernot B. A hybrid micro-macroevolutionary approach to gene tree reconstruction. J Comput Biol. 2006;13:320-35.

21. Stitz M, Hartl M, Baldwin IT, Gaquerel E. Jasmonoyl-I-Isoleucine coordinates metabolic networks required for anthesis and floral attractant emission in wild tobacco (Nicotiana attenuata). Plant Cell. 2014: 26:3964-3983.

22. Woldemariam MG, Dinh ST, Oh Y, Gaquerel E, Baldwin IT, Galis I. NaMYC2 transcription factor regulates a subset of plant defense responses in Nicotiana attenuata. BMC Plant Biol. 2013;13:73.

23. Kim SG, Yon F, Gaquerel E, Gulati J, Baldwin IT. Tissue specific diurnal rhythms of metabolites and their regulation during herbivore attack in a native tobacco, Nicotiana attenuata. PLoS One. 2011;6:e26214.

24. Wagner GP, Kin K, Lynch VJ. Measurement of mRNA abundance using RNAseq data: RPKM measure is inconsistent among samples. Theory Biosci. 2012;131:281-5

25. Li D, Baldwin IT, Gaquerel E. Navigating natural variation in herbivoryinduced secondary metabolism in coyote tobacco populations using MS/ MS structural analysis. Proc Natl Acad Sci U S A. 2015;E4147-55.

26. Li D, Heiling S, Baldwin IT, Gaquerel E. Illuminating a plant's tissue-specific metabolic diversity using computational metabolomics and information theory. Proc Natl Acad Sci U S A. 2016;E7610-E7618.

27. Ma C, Wang X. Application of the Gini correlation coefficient to infer regulatory relationships in transcriptome analysis. Plant Physiol. 2012;160: 192-203.

28. Ochiai A. Zoogeographic studies on the soleoid fishes found in Japan and its neighbouring regions. Bull Japanese Soc Sci Fish. 1957;22:526-30.

29. Li S, Pandey S, Gookin TE, Zhao Z, Wilson L, Assmann SM. Gene-sharing networks reveal organizing principles of transcriptomes in Arabidopsis and other multicellular organisms. Plant Cell. 2012:24:1362-78.

30. Winter D, Vinegar B, Nahal H, Ammar R, Wilson G V, Provart NJ. An "Electronic Fluorescent Pictograph" browser for exploring and analyzing large-scale biological data sets. PLoS One. 2007;2:e718. 
31. Gulati J, Kim S-G, Baldwin IT, Gaquerel E. Deciphering herbivory-induced gene-to-metabolite dynamics in Nicotiana attenuata tissues using a multifactorial approach. Plant Physiol. 2013;162:1042-59.

32. Gulati J, Baldwin IT, Gaquerel E. The roots of plant defenses: Integrative multivariate analyses uncover dynamic behaviors of gene and metabolic networks of roots elicited by leaf herbivory. Plant J. 2014;77:880-92.

33. Gaquerel E, Kuhl C, Neumann S. Computational annotation of plant metabolomics profiles via a novel network-assisted approach. Metabolomics. 2013;9:904-18.

34. Allen E, Moing A, Ebbels TM, Maucourt M, Tomos AD, Rolin D, et al. Correlation network analysis reveals a sequential reorganization of metabolic and transcriptional states during germination and genemetabolite relationships in developing seedlings of Arabidopsis. BMC Syst Biol. 2010;4:62.

35. Letunic I, Bork P. Interactive Tree Of Life (iTOL): an online tool for phylogenetic tree display and annotation. Bioinformatics. 2006;23:127-8.

36. Letunic I, Bork P. Interactive Tree Of Life v2: online annotation and display of phylogenetic trees made easy. Nucleic Acids Res. 2011;39:W475-8.

37. Chae L, Kim T, Nilo-Poyanco R, Rhee SY. Genomic signatures of specialized metabolism in plants. Science. 2014;344:510-3.

38. Gaquerel E, Gulati J, Baldwin IT. Revealing insect herbivory-induced phenolamide metabolism: From single genes to metabolic network plasticity analysis. Plant J. 2014;79:679-92.

39. Edreva AM, Velikova VB, Tsonev TD. Phenylamides in plants. Russ J Plant Physiol. 2007;54:287-301.

40. Onkokesung N, Gaquerel E, Kotkar H, Kaur H, Baldwin IT, Galis I. MYB8 controls inducible phenolamide levels by activating three novel hydroxycinnamoyl-coenzyme A:polyamine transferases in Nicotiana attenuata. Plant Physiol. 2012;158:389-407.

\section{Submit your next manuscript to BioMed Central and we will help you at every step:}

- We accept pre-submission inquiries

- Our selector tool helps you to find the most relevant journal

- We provide round the clock customer support

- Convenient online submission

- Thorough peer review

- Inclusion in PubMed and all major indexing services

- Maximum visibility for your research

Submit your manuscript at www.biomedcentral.com/submit

) Biomed Central 